\title{
Implementasi Website Berbasis Search Engine Optimization (SEO) Sebagai Media Promosi
}

\author{
Mardhiya Hayaty ${ }^{\mathbf{1}}$, Dwi Meylasari ${ }^{2}$ \\ ${ }^{1}$ Informatika, Universitas Amikom Yogyakarta \\ e-mail:mardhiya_hayati@amikom.ac.id \\ ${ }^{2}$ Sistem Informasi, Universitas Amikom Yogyakarta \\ e-mail:meylasari8861@students.amikom.ac.id
}

\begin{abstract}
Abstrak
Kemajuan teknologi informasi berkembang secara pesat di berbagai bidang kehidupan. Internet adalah salah satu bagian dari teknologi informasi dan komunikasi mempunyai efek dan pengaruh yang sangat besar. Website salah satu teknologi internet tidak hanya sebagai media informasi tetapi menjadi proses pendukung bisnis perusahaan, akan tetapi penjualan melalui website belum cukup efektif jika tidak didukung dengan strategi promosi yang baik. SEO (Search Engine Optimization) adalah salah satu teknik promosi dengan cara memanfaatkan pengoptimalan mesin pencari agar website yang sudah kita buat berada diperingkat teratas atau halaman pertama (first page) sebuah halaman mesin pencari. Peneltian ini dilakukan pada sebuah website yang awalnya belum dilakukan teknik-teknik dari SEO, kemudian dengan menerapkan metode SEO on Page seperti optimasi keyword pada title tag, content, meta keyword,meta description, dan share ke sosial media, pada tahap ini juga dilakukan beberapa pengujian sebagai tolak ukur keberhasilan penerapan teknik-teknik SEO. Hasil dari penerapan teknik-teknik SEO mampu meningkatkan SERP (Search Engine Results Page) website di mesin pencari dan berhasil terindek oleh google berada di page kedua pada bulan kedua dan berhasil terindex di page pertama dalam pencarian google denga waktu kurang dari 3 bulan.
\end{abstract}

Kata Kunci : Website, SEO, Seo on Page, SERP

\begin{abstract}
The advancement of information technology is growing rapidly in various fields of life. The internet is one part of information and communication technology has a very large effect and influence. The website not only serves as a medium of information but supports the company's business, but sales through the website are not effective enough if it is not supported by a good promotional strategy. SEO (Search Engine Optimization) is a promotional technique by utilizing search engine optimization so that the website we have created is at the top or first page (first page) of a search engine page. This research was conducted on a website that has not been done techniques from SEO, then by applying the SEO on Page method such as keyword optimization on title tags, content, meta keywords, meta description, and sharing to social media, at this stage several tests are also carried out. as a benchmark for the successful application of SEO techniques. The results of the application of SEO techniques are able to increase the SERP (Search Engine Results Page) of websites in search engines and successfully indexed by Google on the second page in the second month and successfully indexed on the first page in google search with less than 3 months.
\end{abstract}

Keywords: Website, SEO, Seo on Page, SERP

\section{Pendahuluan}

Kemajuan teknologi informasi

berkembang secara pesat di berbagai bidang kehidupan(Tendean, Rumokoy, \& Program, 2018). Internet adalah salah satu bagian dari teknologi informasi dan komunikasi mempunyai efek dan pengaruh yang sangat besar terhadap kehidupan, dengan internet manusia bisa berkomunikasi tanpa batas diberbagai wilayah di dunia, jumlah pengguna internet semakin meningkat secara signifikan setiap tahun (A. Riyanto, 2018).

Website salah satu teknologi internet tidak hanya sebagai media informasi tetapi menjadi proses pendukung 
bisnis perusahaan seperti penjualan produk dan jasa secara online(Hidayat, Marlina, \& Utami, 2017), akan tetapi penjualan melalui website belum cukup efektif jika tidak didukung dengan strategi promosi yang baik. SEO (Search Engine Optimization) adalah salah satu teknik promosi dengan cara memanfaatkan pengoptimalan mesin pencari agar website yang sudah kita buat berada diperingkat teratas atau halaman pertama (first page) (Halilintar \& Ariyus, 2018) sebuah halaman mesin pencari.

Penelitian sebelumnya telah dilakukan penerapan teknik SEO yaitu metode white hat SEO pada sebuah website dan berhasil berada diposisi peringkat teratas dan aman dari proses deindex(A. Riyanto, 2018), telah diteliti bahwa proses index lebih cepat pada expired domain dibandingkan fresh domain pada mesin pencari google khususnya proses image-index akan tetapi fresh domain lebih stabil dalam peningkatan index(Sujatmiko \& Ariyus, 2018)

Snap Art Photography adalah sebuah perusahaan yang bergerak dibidang bisnis jasa fotografi. Promosi yang telah dilakukan selama ini masih bersifat konvensional, target pemasaran sempit, biaya iklan cukup besar sehingga tidak bisa menghasilkan target profit yang diinginkan, selain itu trafik kunjungan website sangat rendah sehingga tidak terlihat atau masih berada pada halaman yang jauh dari Search Engine Results Page (SERP).

Untuk mengatasi hal tersebut, dengan dukungan teknologi informasi penelitian ini bertujuan untuk mengimplementasikan pembuatan website dan menerapkan teknik SEO pada Snap Art Photography agar target pemasaran menjadi lebih luas, bisnis didalam website semakin berkembang sehingga penjualan semakin meningkat.

\section{Pemasaran dan Promosi}

Promosi adalah faktor penting dalam pemasaran sebuah produk(Abshor, Hasiholan, \& Malik, 2018), promosi sebuah kegiatan yang dilakukan untuk mengenalkan produk yang akan dijual, melalui promosi diharapkan jangkauan pemasaran menjadi semakin luas dan dapat meningkatkan target penjualan.

\section{Website}

Website sebuah aplikasi yang bisa diakses oleh semua orang diberbagai wilayah dengan menggunakan jaringan
Internet. Sebuah halaman website mempunyai informasi dokumen-dokumen seperti text, gambar, suara, video menggunakan protokol HTTP (hypertext transfer protokol)(Hasugian, 2018). Banyak fitur yang bisa dimanfaatkan pada sebuah halaman website yaitu sebagai media informasi dan promosi sebuah produk atau jasa.

SEO

SEO adalah teknik yang digunakan agar website dapat dikenal dengan mudah oleh mesin pencari sehingga dapat meningkatkan pengunjung website, terdapat 2 macam teknik SEO yaitu SEO on page dan SEO off page. SEO on page adalah teknik-teknik yang digunakan pada halaman website dengan cara memodifikasi bagianbagian website seperti content, link, tag, kata kunci(Himawan, Arisantoso, \& Saefullah, 2017), sedangan SEO off page adalah teknik yang dilakukan diluar website(A. D. Riyanto \& Purwadi, 2016).

\section{Metode Penelitian Alur Penelitian}

Penelitian ini dimulai dengan identifikasi masalah - masalah yang muncul pada website yang telah ada, setelah itu dilakukan tahap studi literatur dalam rangka memperkaya wawasan untuk memperbaiki masalah-masalah tersebut, selanjutnya pada tahap berikutnya adalah perancangan teknik-teknik SEO berdasarkan analisaanalisa identifikasi masalah dan studi literatur yang telah dilakukan. Dilakukan tahapan pengujian dan perubahan rancangan untuk hasil yang lebih baik, tahapan terakhir adalah implementasi website dengan teknik-teknik SEO yang telah diterapkan. Alur penelitian seperti gambar dibawah ini :

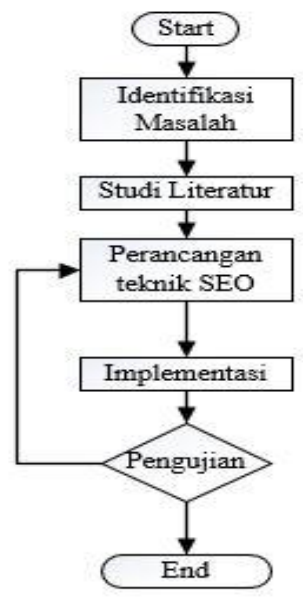

Gambar 1. Alur Penelitian 
Perancangan untuk mengoptimalkan posisi website agar berada dihalaman pertama dengan menggunakan teknik SEO,

Hal-hal yang dilakukan pada teknik SEO on Page adalah(A. Riyanto, 2018) :

1. Title tags

Memberikan penyisipin keyword pada title pada halaman website.

2. Meta keyword dan meta description

Memberikan keyword yang telah ditentukan agar website mudah dicari oleh mesin pencari dan menjelaskan content yang dibuat, dalam meta decription dengan panjang 150-160 karakter

3. Heading tag

Memberikan tag ALT dan tag TITLE pada setiap gambar untuk mendefinisikan gambar tersebut.

4. URL structure

5. Image

6. Content

Memberikan penebalan pada kata-kata dari isi sebuah artikel sebagai penanda keyword.

Keyword (kata kunci) merupakan satu hal yang penting dari optimalisasi SEO, dengan memilih kata kunci yang tepat maka webiste akan semakin banyak memilliki pengunjung(ID hadiana, 2018). Keyword sebagai subjek pencarian sebuah halaman website(Halilintar \& Ariyus, 2018). Keyword diletakkan pada title tag atau judul dari sebuah dokumen karena judul merupakan relevansi dari keyword atau informasi yang dicari oleh pengunjung.

Content merupakan salah satu aspek penting dalam SEO, artikel pada sebuah content tidak hanya untuk untuk kemudahan mesin pencari tetapi content yang baik mengandung unsur pendidikan yang dapat mengedukasi pembaca.(Septa, Hamzah, \& Andayati, 2014)

Beberapa mesin pencari menggunakan proses perhitungan berapa banyak link yang dapat berhubungan antara halaman web dengan website yang lain(Himawan et al., 2017). Semakin banyak link yang dimiliki maka akan mendapatkan peringkat yang lebih baik dari mesin pencari.

Pemberian button/link ke sosial media memudahkan pengunjung untuk berbagi informasi kepada pengunjung yang lain, sehingga jumlah pengunjung diharapkan semakin meningkat(Septa et al., 2014).

\section{Implementasi}

Implementasi dilakukan mengacu pada rancangan teknik SEO yang telah dirancang.

\section{Pengujian}

Pengujian dilakukan dengan mengukur pagespeed, waktu loading dan lain-lain. Pengujian juga dilakukan untuk menilai responsive design pada halaman website pada berbagai perangkat.

\section{Hasil dan Pembahasan}

Website snapart telah dioptimasi menggunakan metode SEO On Page dengan beberapa teknik dan telah dilakukan pengujian yaitu kecepatan loading website, responsive design serta pengamatan posisi website dimesin pencari.

\subsection{Implementasi metode Seo On Page}

Penerapan dan Implementasi SEO On Page ini meliputi beberapa hal, yaitu :

Optimasi title, title dioptimalisasikan dengan keyword, dimana keyword akan disisipkan pada character pertama pada title agar tidak terpotong oleh mesin pencari. Seperti contoh artikel dengan judul "Lomba Agustusan foto studio Kulon Progo - Snap Art Studio" disisipi dengan keyword "fotostudio kulon progo". Title diambil dari colom title pada database tabel artikel. Script Program bisa dilihat pada script di bawah ini.

\section{Script 1. Tag H2}

\begin{tabular}{l}
\hline ch2 class="detail-title rolor-dark-2">Lomba \\
Agustusan foto studio Kulon Progo - Snap Art $</ h 2>$
\end{tabular}

Pada Halaman Home Title artikel akan menggunakan tag $\mathrm{H} 2<\mathrm{h} 2>$. seperti terlihat pada gambar berikut ini.

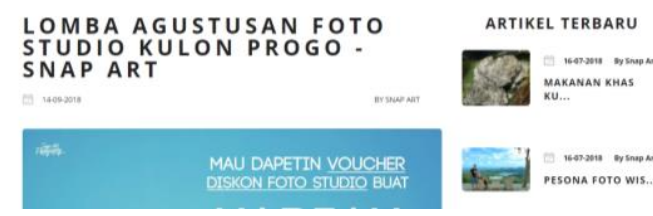

Gambar 2. Hasil Tag H2 Optimasi URL, dengan menyisipkan keyword utama sebagai contoh diatas menggunakan keyword 
"studio foto kulon progo". URL diambil dari colom title pada database artikel, berikut ini listing programnya.

Script 2. Optimasi URL

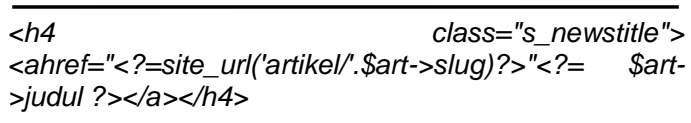
bawah in

Sehingga URL seperti gambar di

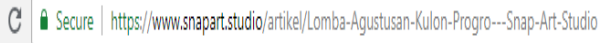

Gambar 3. Hasil optimasi URL

Penggunaan Meta Description berfungsi untuk menjalankan secara singkat dan jelas tentang apa isi dari content/ artikel yang dicari oleh visitor. Meta tag ini membantu web spider atau robot search engine dalam mendeskripsikan artikel dalam web. Meta Description diambil dari colom Description dari database tabel artikel.

Meta Keywords berguna untuk menentukan kata kunci pada sebuah content agar dapat bersaing di mesin pencari. Kata kunci harus sesuai dengan isi dari artikel pada web. Meta Keywords ini juga berfungsi untuk membuat content/artikel lebih cepat terindeks search engine berdasarkan kata kunci yang ditentukan. Meta Keywords diambil dari colom keywords pada database tabel artikel.

Penggunaan meta description dan meta keywords dapat dilihat pada script program berikut ini.

Script 3. Meta description dan meta keyword

$<$ Meta name="keyword" content="SnapArt Studio Foto KulonProgo, Foto Studio Foto Kulon Progo, Studio Foto, Yogyakarta, Paket Foto, Prawedding, Wedding, Graduation, Wisuda">

$<$ meta name="description" content="Studio Foto Kulon Progo, Studio Foto KulonProgo, Studio Foto Wates, Studio Foto Yogyakarta, snapart.studio, Wedding KulonProgo, Wedding Kulon Progo, Prewedding KulonProgo, Prewedding Kulon Progo"s

Pada setiap gambar yang ada, akan diberi tag ALT dan tag TITLE untuk mendefinisikan gambar tersebut. Tag tersebut juga membuat gambar terindek oleh mesin pencari. title dari gambar diambil dari colom foto pada database table, listing program seperti gambar di bawah ini.

Script 4. Tag pada Gambar

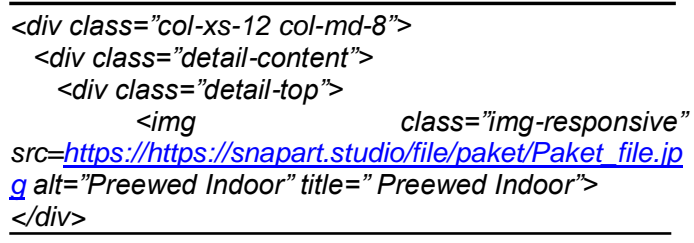

Optimasi SEO on page selanjutnya adalah optimasi content. Content berarti isi dari artikel. Content dibuat dengan minimal kata. Dan content dibuat unik dan bermanfaat untuk visitor yang membaca content tersebut. Pada content terhadap beberapa kata yang ditebalkan. Kata ini adalah sebagai penanda keyword dalam content/artikel. Content/artikel diambil dari colom text pada database tabel artikel.

Implementasi Internal link berguna sebagai link yang berkaitan dengan content /artikel pada website. Internal link berguna untuk memperbanyak page view dari website.

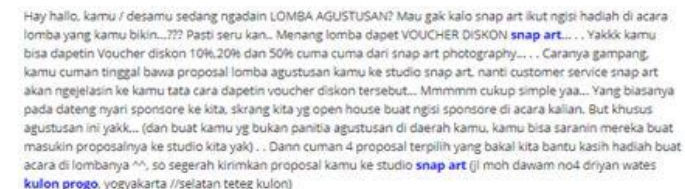

Gambar 4. Implementasi Internal Link

Pada setiap artikel akan diberi tombol sharing ke social media seperti facebook, twitter dan google. Tombol ini berguna untuk membagi artikel ke media social agar dapat mendapat visitor dan backlink dari media social.

kulon progo, yogyakarta ///selatan teteg kulon]

SHARE:

Gambar 5. sharing ke social media

\subsection{Pengujian}

Kecepatan pada website telah diuji menggunakan tools gtmetrix bahwa website snapart.studio memiliki PageSpeed 94\% dengan grade A. Dan memiliki waktu loading website 2,9 second. Ukuran dari website tersebut hanya $1.22 \mathrm{Mb}$. Seperti yang telah ditunjukkan pada gambar berikut ini : 


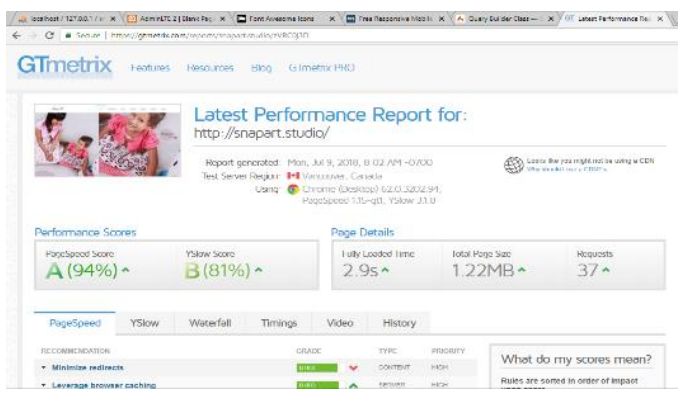

Gambar 6. Uji kecepatan

Tampilan layout website dibuat menjadi responsive design, yaitu website dapat menyesuaikan tampilan layout ketika di buka disemua device.

Teknik-teknik dari SEO telah diuji pada website snapart.studio yang sudah diopimasi menggunakan metode SEO On Page. Hasil pengujian dengan kata kunci Studio Foto Kulonprogo berhasilkan menempatkan website tersebut pada mesin pencari dengan posisi page ke-2 pada bulan juni 2018 (bulan ke-2) yang sebelumnya sama sekali tidak terlacak pada mesin pencari, kemudian pada bulan juli 2018 (bulan ke-3) naik peringkat berada di posisi page pertama. Berikut ini adalah hasil uji pencarian di mesin pencari google bulan ke-2 dan bulan ke-3 :

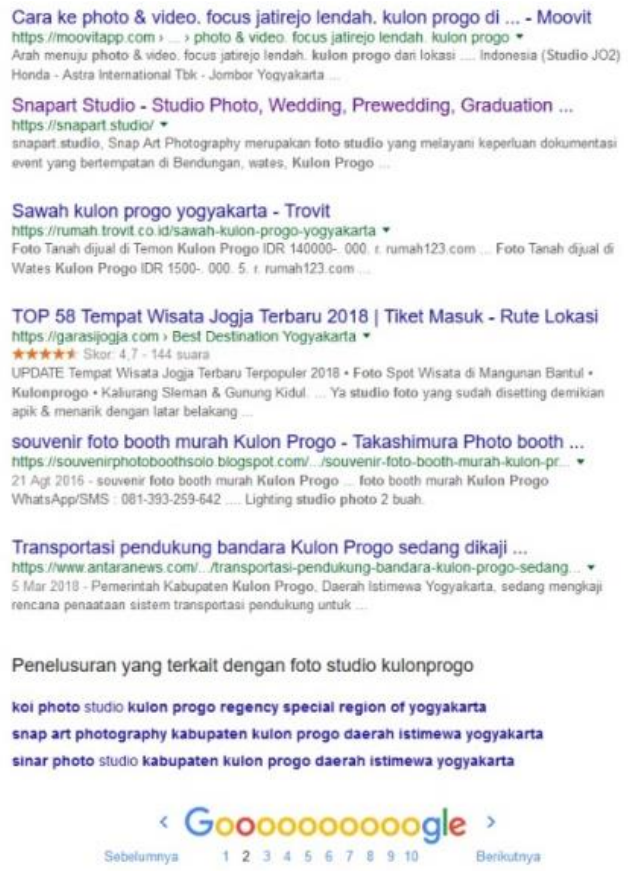

Gambar 7. Posisi di mesin pencari google (page kedua)
SnapArt.studio: Studio Foto Kulon Progo, Yogyakarta https://snapart.studio/ - Translate this page

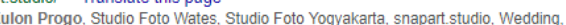
Prewedding

Snap Art Photography

oto.blogspot.com/ - Translate this pag

Melayani : - Foto Studio - Foto Prewedding Foto Wedding - Foto Personal / Couple - Foto Keluarga - Foto

Snap Art Photography (@snapartphoto)•Instagram photos and videos https://www

15.2k Followers, 2787 Following, 2867 Posts - See Instagram photos and videos from Snap Art Photography (@snapartphoto)

Koi Photography Studio - Yogyakarta - Photographer | Facebook https://www.facebook.com/pages/Koi-Photography-Studio/1447562485491751

Phone, +62 856-4324-2060 ... Diah KusumanyaEdy Xixixi...., bu sum ada fotonya, td foto di sana tapi kayaknya ga distudio, cuma mungkin blm diuploa

Edi Karya Studio Foto - Tersedia Rias Pengantinnya Juga Loh https://edi-karya-studio-foto.business.site/ Translate this page

. Pakt Lentuk Konsep Foto Weddingmu. Peta yang . Kulon Progo.

Foto Studio Cahaya

https://foto-studio-cahaya. business.site/ - Translate this pag

Janatkan petuniuk arah; Kontak 0856-0190-4421. Jam Buka

\section{Go000000000gle >}

Gambar 8. Posisi di mesin pencari google (page pertama)

\section{Kesimpulan}

Penerapan teknik SEO On Page dapat meningkatkan SERP website di mesin pencari dan mendapat traffic visitor dari mesin pencari google. Website snap.studio yang semula tidak terindex telah berhasil terindek oleh google berada di page pertama dalam pencarian google dengan waktu kurang dari 3 bulan. Untuk penelitian selanjutnya adalah menggunakan optimasi dengan teknik lain yaitu SEO off page sehingga posisi pencarian website bertahan lama pada halaman page 1.

\section{Referensi}

Abshor, M. U., Hasiholan, L. B., \& Malik, D. (2018). Pengaruh harga, promosi dan kualitas produk terhadap keputusan pembelian produk torabika duo.

Halilintar, R. B., \& Ariyus, D. (2018). Implementasi Seo ( Search Engine Optimization ) Pada Website Agc ( Auto Generated Content ) Untuk Meningkatkan Serp ( Search Engine Result Page ) Studi Kasus: Website Gallery (pp. 13-18).

Hasugian, P. S. (2018). Perancangan Website Sebagai Media Promosi Dan. Journal of Informatic Pelita NUsantara, 3(1), 82-86. 
Hidayat, R., Marlina, S., \& Utami, L. D. (2017). Perancangan Sistem Informasi Penjualan Barang Handmade Berbasis Website Dengan Metode Waterfall. Simposium Nasional IImu Pengetahuan Dan Teknologi (SIMNASIPTEK), 1, 175183. Retrieved from http://seminar.bsi.ac.id/simnasiptek/in dex.php/simnasiptek2017/article/view/138

Himawan, Arisantoso, \& Saefullah, A. (2017). Search Engine Optimization (SEO) Menggunakan Metode White Hat SEO Untuk Meningkatkan Peringkat dan Trafik Kunjungan Website. In Seminar Nasional Teknologi dan Informatika 2017 (pp. 783-790).

ID hadiana, A. (2018). Model Search Engine Optimization bagi Usaha Mikro Kecil dan Menengah ( UMKM ) di Bandung Barat. JUMANJI, 2(1), 3138.

Riyanto, A. (2018). Analisis Dan Penerapan Search Engine Optimization Pada Website Menggunakan Metode White Hat Seo. JURNAL TEKNOLOGI INFORMASI, 1.

Riyanto, A. D., \& Purwadi. (2016). Penerapan Teknik Search Engine Optimization ( SEO ) untuk Memenangkan Persaingan Kata Kunci pada Mesin Pencari Google ( Implementation Techniques Search Engine Optimization ( SEO ) for Winning Competition Keywords on Google Search Engines ( Case Study: C. JUITA Jurnal Informatika, IV(November), 59-65. Retrieved from http://jurnalnasional.ump.ac.id/index.p hp/JUITA/article/view/1334/1174

Septa, R., Hamzah, A., \& Andayati, D. (2014). Analisis dan Implementasi Penggabungan Dua Teknik SEO untuk Meningkatkan SERP Website pada Algoritma Google Terbaru. Jurnal SCRIPT, 2(1), 26-33.

Sujatmiko, S., \& Ariyus, D. (2018). Analisis Google Image Index Perbandingan SEO Expired Domain dan Fresh Domain Studi Kasus Toko Online (pp.
25-30).

Tendean, N. I., Rumokoy, F. S., \& Program, M. (2018). The Effectiveness of Internet Marketing Strategy of Emerging Business in Increasing Brand Awareness ( Case Study of Bon-Bon Pisang Nugget Manado). Jurnal EMBA, 6(2), 938-947 